\title{
EFEITO DO COZIMENTO SOBRE ALGUNS FATORES ANTINUTRICIONAIS EM FOLHAS DE BRÓCOLI, COUVE-FLOR E COUVE ${ }^{1}$
}

\author{
Effect of boiling on contents of antinutritional factors in leaves of broccoli, \\ cauliflower and cabbage
}

\author{
Mônica Alessandra Teixeira dos Santos ${ }^{2}$
}

\begin{abstract}
RESUMO
Os resíduos vegetais desprezados pela indústria e durante o preparo dos alimentos poderiam ser utilizados como fontes alternativas de nutrientes contribuindo para o enriquecimento da dieta das populações carentes. Por outro lado, muitos alimentos vegetais são fontes de fatores antinutricionais que interferem na digestão ou absorção de nutrientes. Determinou-se os teores de polifenóis, nitrato e ácido oxálico de folhas de brócoli, couve-flor e couve submetidas à cocção por seis diferentes tempos $(0,2,4,6$, 8 e 10 minutos). Verificou-se queda nos teores de fatores antinutricionais com o aumento do tempo de cozimento, mostrando-se aceitáveis para o consumo. No entanto, os tratamentos utilizados não foram suficientes para reduzir os teores de polifenóis das folhas de brócoli e couve a valores considerados adequados ao consumo humano, sugerindo a utilização conjunta de outra metodologia para a redução dos polifenóis presentes nesses vegetais.
\end{abstract}

Termos para indexação: Fatores antinutricionais, folhas, cozimento, Brassica spp.

\begin{abstract}
The vegetable residues despised from the industry and during the food preparation might be used as an alternative nutrient source that provides poor people a richer diet. Otherwise, many vegetables are source of antinutritional factors that might influence in the digest or in the nutrients absorption. As the purpose to determining the contents of poliphenols, oxalic acid and nitrate in leaves of broccoli, cauliflower and cabbage, they were submitted to cooking in six different times $(0,2,4,6,8$ and 10 minutes). The results showed that the antinutritional factors dropped with the increase of the cooking time, being acceptable for the consumption. However, the treatments were not enought to decrease the contents of poliphenols in leaves of broccoli and cabbage considering values to the human consumption. Thus, it had better to use another methodology to decrease the level of polyphenols in the vegetables.
\end{abstract}

Index terms: Antinutritional factors, leaves, boiling, Brassica spp.

(Recebido para publicação em 11 de agosto de 2004 e aprovado em 2 de fevereiro de 2005)

\section{INTRODUÇÃO}

A família Brassicaceae (Cruciferae) apresenta várias espécies economicamente importantes para o uso como hortaliças, forragens, óleo, bem como plantas ornamentais e medicinais (GRIFFITHS et al., 1998). O consumo de vegetais crucíferos, particularmente o brócoli, tem sido associado com a redução do risco de câncer de mama em mulheres na pré-menopausa (AMBROSONE et al., 2004), devendo ser consumidos diariamente. Além dos efeitos anticarcinogênicos, as brássicas são nutricionalmente importantes devido aos elevados teores de vitamina $\mathrm{C}$, minerais e fibras, encontrados nas inflorescências e folhas dessas hortaliças (BLOCK, 1991; SANTOS, 2000).

Diante da importância nutricional atribuída à família das brássicas, o consumo dessas hortaliças poderia ser realizado de forma integral . No entanto, apenas as inflorescências da couve-flor e brócoli são aproveitadas, correspondendo a parte comestível e industrializável. O restante (folhas e caules) considerado resíduo agrícola, é desprezado e poderia ser utilizado como fonte alternativa de nutrientes com um papel importante em dietas balanceadas.

Todavia, para utilização de folhas vegetais como fonte alternativa de nutrientes, é necessário o conhecimento da presença de fatores antinutricionais e/ou tóxicos que possam afetar o valor nutricional dos alimentos.

O termo "fator antinutricional" tem sido usado para descrever compostos ou classes de compostos presentes numa extensa variedade de alimentos de origem vegetal, que quando consumidos, reduzem o valor nutritivo dos alimentos. Eles interferem na digestibilidade, absorção ou utilização de nutrientes e, se ingeridos em altas concentrações, podem acarretar em efeitos danosos à saúde (GRIFFITHS et al., 1998).

\footnotetext{
${ }_{1}^{1}$ Parte da dissertação apresentada à Universidade Federal de Lavras/UFLA - Cx. P. 3037 - 37200-000 - Lavras, MG, pela autora, para obtenção do título de Mestre em Ciência dos Alimentos.

${ }^{2}$ Mestre em Ciência dos Alimentos pela Universidade Federal de Lavras/UFLA - Cx. P. 3037 - 37200-000 - Lavras, MG - monicas@fea.unicamp.br
} 
Vários tipos de fatores antinutricionais têm sido identificados nos vegetais crucíferos. Os taninos constituem um dos compostos de maior relevância entre essas espécies (GRIFFITHS et al., 1998). Os taninos estão incluídos no grupo dos polifenóis, substâncias naturais mais numerosas e extensamente distribuídas no reino vegetal (REYES-MORENO \& PAREDES-LÓPEZ, 1993). Os taninos formam complexos com as proteínas, tornando-as insolúveis e inativando enzimas. Além disso, se ligam a outras macromoléculas como o amido, causando a redução no valor nutricional dos alimentos (CHUNG et al., 1998; GUZMÁN-MALDONADO et al., 2000). A complexação dos taninos com as proteínas é a base principal do efeito biológico e é dependente do $\mathrm{pH}$. Portanto, é reversível e envolve ligações hidrofóbicas e pontes de hidrogênio (HASLAN, 1966).

São atribuídos aos taninos outros efeitos prejudiciais à dieta, como cor indesejável aos alimentos, devido as reações de escurecimento enzimático e diminuição da sua palatabilidade, devido à adstringência. Liener (1994) atribui aos taninos outros efeitos antinutricionais, como danos à mucosa intestinal e interferência na absorção de ferro, glicose e vitamina $B_{12}$.

De acordo com Chung et al. (1998), a incidência de alguns tipos de câncer, como o câncer de esôfago, têm sido relatados estarem relacionados ao consumo de dietas ricas em taninos. No entanto, trabalhos (GEHM et al., 1997; JANG et al., 1997) indicam que os polifenóis (principalmente os flavonóides) das uvas vermelho-roxas escuras, apresentam a capacidade de prevenir o risco de doenças cardiovasculares. $\mathrm{O}$ vinho tinto também contribui com um alto conteúdo destes compostos, sendo 20 a 50 vezes maior do que no vinho branco.

Além disso, os taninos se apresentam importantes em alguns setores da indústria, como na produção de cerveja, em que contribui para a estabilização do produto por meio da redução da sua concentração protéica (REINOLD, 1997). A produção de resinas e o curtimento de pele animal para produção de couro são outras áreas de atuação dos taninos (LELIS \& GONÇALVES, 2001).

Os vegetais também são fontes naturais de nitrato, composto utilizado como fonte de nitrogênio para o crescimento das plantas. Estima-se que os vegetais, em particular os verdes folhosos, contribuam com mais de $70 \%$ do nitrato total ingerido. No entanto, as concentrações normais de nitrato e nitrito nos alimentos naturais dependem do uso de fertilizantes e das condições nas quais os alimentos são cultivados, colhidos e armazenados (WALKER, 1975; GUADAGNIN, 2004).
A importância do nitrato para a saúde humana está na sua transformação em nitrito pelo organismo. A redução intestinal de nitrato a nitrito, com conseqüente absorção do mesmo, poderia originar cianoses devido a formação de metamioglobina. O nitrito também reage com aminas secundárias e terciárias formando compostos $\mathrm{N}$-nitrosos (LINDSAY, 1993; WALKER, 1990), potencialmente carcinogênicos.

O oxalato, freqüentemente encontrado em vegetais como o espinafre, ruibarbo, acelga, beterraba, tomate, nozes e cacau (KRAUSE \& MAHAN, 1991; MASSEY et al., 1993), quando absorvido, não pode ser metabolizado pelos humanos e é excretado na urina. A elevada quantidade de oxalato na urina aumenta o risco da formação de cálculos de oxalato de cálcio nos rins, pois o oxalato de cálcio é pouco solúvel na urina (MANDEL, 1996; MASSEY et al., 1993), podendo também causar irritações na mucosa intestinal (ESPÍNDOLA, 1987).

Considerando a grande quantidade de resíduos produzidos na horticultura e a importância do estudo de fatores antinutricionais para a saúde humana, determinouse os teores de polifenóis, nitratos e ácido oxálico em folhas de brócoli e couve-flor, geralmente não consumidas, e estas foram comparadas com a couve-comum (tradicionalmente consumida), submetendo-as a diferentes tempos de cozimento.

\section{MATERIAL E MÉTODOS}

Este experimento foi conduzido no Laboratório de Análise de Produtos Vegetais do Departamento de Ciência dos Alimentos da Universidade Federal de Lavras (UFLA), em Lavras, Minas Gerais.

Foram utilizadas folhas de brócoli (Brassica oleracea L. var. botrytis-asparagoides), couve-flor (Brassica oleracea L. var. botrytis-cauliflora) e couve (Brassica oleracea L. var. acephala) cultivadas no município de Ijaci, Minas Gerais. As folhas foram colhidas pela manhã, levadas ao laboratório onde foram separadas ao acaso em 6 lotes, lavadas em água corrente e novamente em água destilada. Após secas, as folhas foram picadas uniformemente e submetidas à cocção em temperatura de ebulição por $0,2,4$, 6,8 e 10 minutos, com três repetições por tratamento, utilizando 4 litros de água destilada para cada $400 \mathrm{~g}$ de folhas. A água de cozimento foi descartada e o material cozido foi estendido sobre folhas de papel-toalha para a retirada do excesso de água. As folhas foram levadas à estufa ventilada a $60^{\circ} \mathrm{C}$, até peso constante. Posteriormente, foram trituradas em moinho de facas, homogeneizadas e submetidas a análises de alguns fatores antinutricionais. 
O método empregado para determinação dos polifenóis foi o de Swain \& Hillis (1959), utilizando-se água como extrator e dosados de acordo com o método de FolinDenis (AOAC, 1990). Os nitratos foram determinados pelo método colorimétrico de Cataldo et al. (1975) e para o ácido oxálico foi utilizado o método titulométrico com permanganato de potássio, descrito pela AOAC (1990).

$\mathrm{O}$ delineamento experimental foi inteiramente casualizado em esquema fatorial $3 \times 6$, sendo folhas de 3 espécies de brássicas com 6 tempos de cozimento e 3 repetições. Os dados foram submetidos à análise de variância (teste F) e para comparação das médias entre espécies e tempos de cocção foi utilizado o Teste de Tukey, a 5\% de probabilidade. As análises estatísticas foram realizadas segundo técnicas usuais do software SANEST (ZONTA \& MACHADO, 1991).

\section{RESULTADOS E DISCUSSÃO}

Como mostrado na Figura 1, as três espécies estudadas apresentaram queda nos teores de polifenóis (peso fresco) após a aplicação dos tratamentos, sendo a maior perda atribuída às folhas de couve-flor $(66,51 \%)$. As folhas de couve-comum apresentaram os maiores teores de polifenóis e as menores perdas $(58,95 \%)$. Devido à presença de água, os polifenóis encontram-se mais diluídos nas folhas e sua ingestão não favorece a formação dos complexos proteína-tanino, responsáveis pelo decréscimo da digestibilidade de proteínas e conseqüente redução do crescimento do indivíduo (LIENER, 1994).

As três espécies de brássicas analisadas apresentaram teores de polifenóis (peso seco) acima de $1.000 \mathrm{mg} 100 \mathrm{~g}^{-1}$ antes da fervura. Os teores de polifenóis observados são considerados elevados e prejudiciais à digestibilidade de proteínas (HOSENEY et al., 1981). À medida que o tempo de fervura foi aumentado, os teores de polifenóis caíram consideravelmente. As folhas de couve e brócoli mantiveram níveis prejudiciais à saúde mesmo após a aplicação dos tratamentos, corroborando com a revisão realizada por Liener (1994), o qual afirma que os taninos são estáveis em altas temperaturas acarretando uma pequena redução do conteúdo de tanino dos alimentos vegetais submetidos ao processamento térmico. No entanto, segundo o mesmo autor, mergulhar os vegetais em água ou solução salina antes do cozimento reduz significativamente os teores de tanino, desde que a água de cozimento seja descartada.
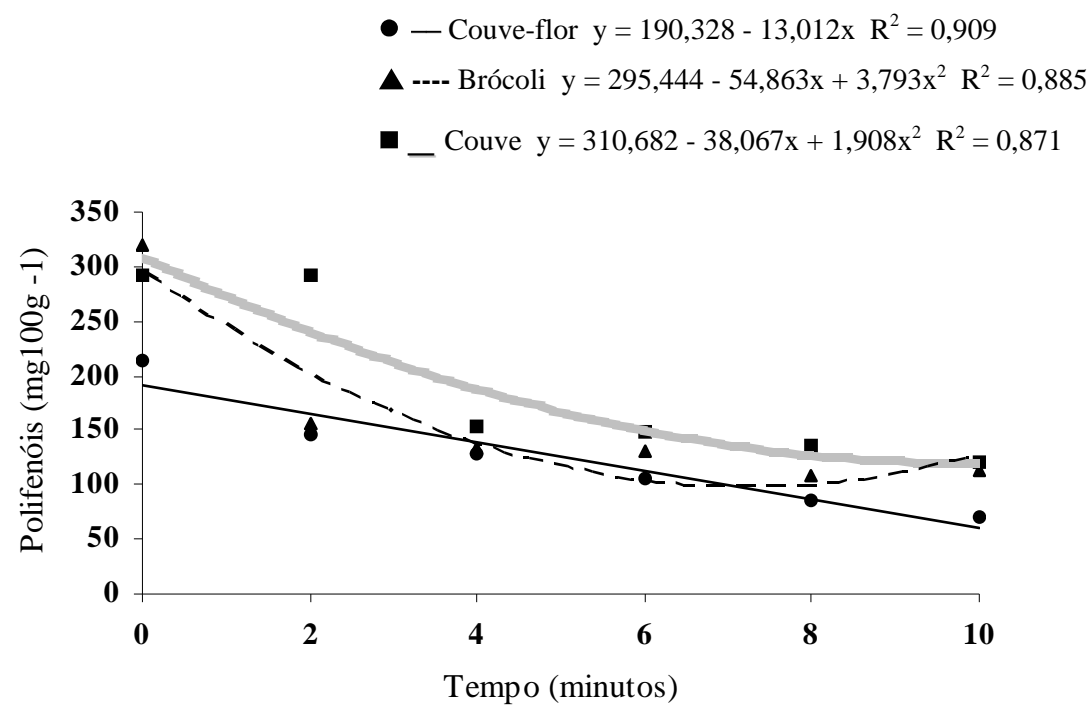

FIGURA 1 - Curvas e equações de regressão representativas dos teores médios de polifenóis das três espécies de brássicas, submetidas a seis tempos de cozimento, expressos em peso fresco.

Ciênc. agrotec., Lavras, v. 30, n. 2, p. 294-301, mar./abr., 2006 


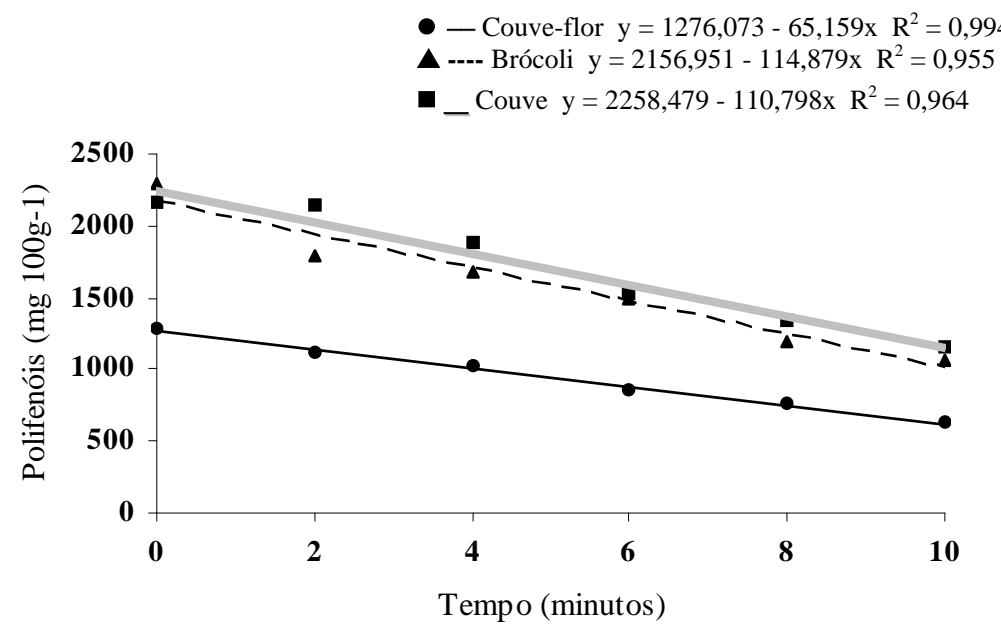

FIGURA 2 - Curvas e equações de regressão representativas dos teores médios de polifenóis das três espécies de brássicas, submetidas a seis tempos de cozimento, expressos em peso seco.

Nas Figuras 3 e 4, observa-se o comportamento do nitrato nas folhas de brócoli, couve-flor e couve, em pesos fresco e seco, com o aumento do tempo de cozimento. Observa-se que as folhas estudadas apresentaram altos teores de nitrato antes da fervura. Após a aplicação dos tratamentos as folhas de brócoli e couve mantiveram, em $100 \mathrm{~g}$ de matéria seca $157,94 \mathrm{mg}$ e $161,12 \mathrm{mg}$, respectivamente, teores inferiores aos encontrados por Pereira et al. (2003) em folhas secas de

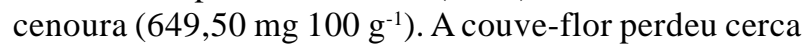
de $62 \%$ do seu conteúdo inicial, permanecendo com $78,14 \mathrm{mg}$ de nitrato em $100 \mathrm{~g}$ (peso seco) no final do cozimento.

A concentração de nitrato varia segundo a espécie dos vegetais. Vegetais verdes folhosos como alface $(230,0$ $\mathrm{mg}$ ) e espinafre $(247,0 \mathrm{mg})$ e raízes como beterraba $(328,1$ $\mathrm{mg}$ ) e rabanete $(260,0 \mathrm{mg})$, destacam-se por acumularem elevados teores de nitrato, geralmente superiores a $100 \mathrm{mg}$ $100 \mathrm{~g}^{-1}$ do produto fresco (MAFF, 1987; WALKER, 1990).

Os teores de nitrato em $100 \mathrm{~g}$ de folhas frescas após a aplicação dos tratamentos apresentaram-se extremamente inferiores aos encontrados por Pinto et al. (2001) em folhas de taioba, consideradas fonte não convencional de nutrientes. Os autores encontraram, respectivamente, valores de $61,49 \mathrm{mg}$ e $82,37 \mathrm{mg}$ em limbos com e sem nervuras; enquanto as brássicas estudadas apresentaram valores médios de $16,6 \mathrm{mg}$ para brócoli e couve e $8,7 \mathrm{mg}$ para couve-flor.

Todas as espécies apresentaram perdas de nitrato ao longo da aplicação dos tratamentos, sugerindo que o cozimento das folhas removeu grande parte deste antinutriente, já que o íon tende a se difundir para a água de cocção (MEAH et al., 1994).

Os teores médios encontrados para ácido oxálico (Figura 5) em $100 \mathrm{~g}$ de matéria seca foram de $60,53 \mathrm{mg}$ no brócoli, 49,66 mg na couve-flor e 38,09 mg na couve. Comparando as médias do presente estudo com as relatadas por Pinto et al. (2001) em folhas de taioba seca

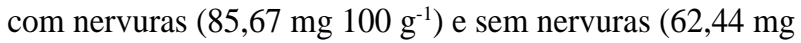
$\left.100 \mathrm{~g}^{-1}\right)$, verifica-se que as brássicas apresentaram teores inferiores, sugerindo esses vegetais como uma melhor opção de consumo.

Após os 10 minutos de fervura verificou-se no material fresco teores médios de ácido oxálico igual a 5,44 mg $100 \mathrm{~g}^{-1}$ (Figura 6 e Tabela 1). O espinafre e o chá preto, importantes fontes de ácido oxálico, apresentam em $100 \mathrm{~g}$ de material fresco teores de $822 \mathrm{mg}$ e $690 \mathrm{mg}$, respectivamente (FRANCO, 1986). Os resultados obtidos se apresentaram extremamente inferiores, sugerindo que as brássicas não contribuem na formação de complexos de oxalato com o cálcio da dieta.

De acordo com os resultados obtidos, a cocção pode ser um método recomendável para a redução de fatores antinutricionais em vegetais, visto que em estudos realizados com taninos, ácido fítico e ácido oxálico ocorreram reduções médias de 30\% após 10 minutos de cozimento doméstico (MOSHA et al., 1995).

Os teores médios das substâncias avaliadas foram expressos em peso fresco e seco e os resultados das análises de variância estão demonstrados nas Tabelas 2 e 3. 


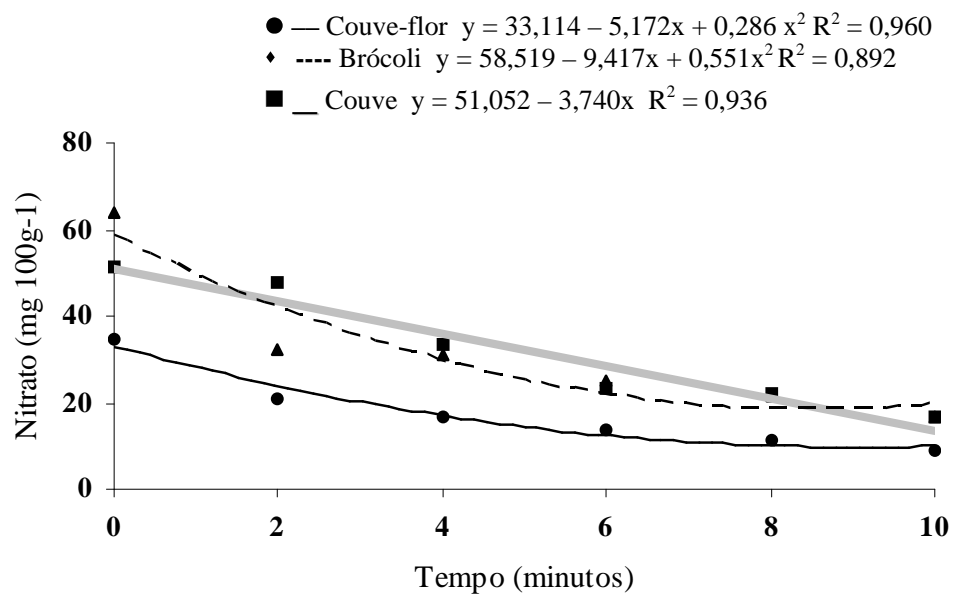

FIGURA 3 - Curvas e equações de regressão representativas dos teores médios de nitrato das três espécies de brássicas, submetidas a seis tempos de cozimento, expressos em peso fresco.

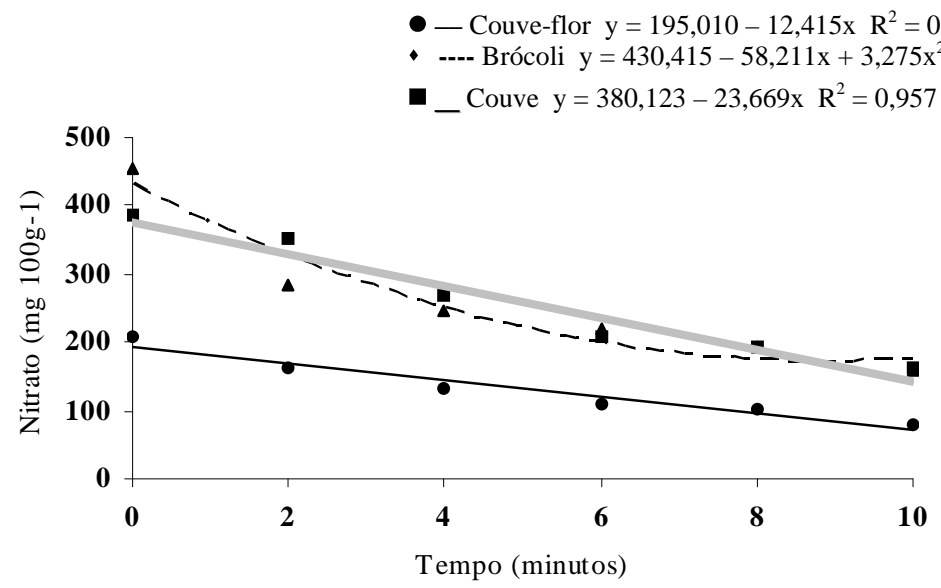

FIGURA 4 - Curvas e equações de regressão representativas dos teores médios de nitrato das três espécies de brássicas, submetidas a seis tempos de cozimento, expressos em peso seco.
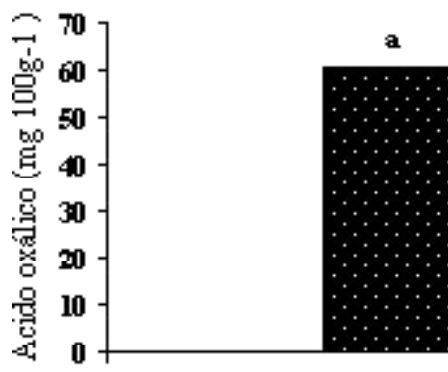

- Brócoli

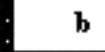

Couve-flor

을 Couve

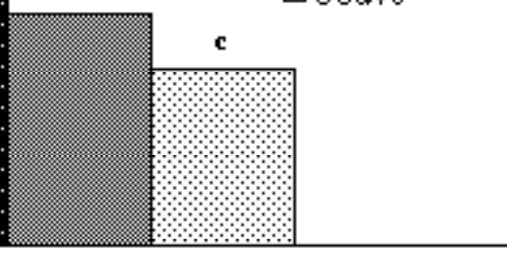

Espécies

FIGURA 5 - Teores médios de ácido oxálico das três espécies de brássicas, expressos em peso seco. Barras com mesma letra não diferem entre si a $5 \%$ de probabilidade.

Ciênc. agrotec., Lavras, v. 30, n. 2, p. 294-301, mar./abr., 2006 


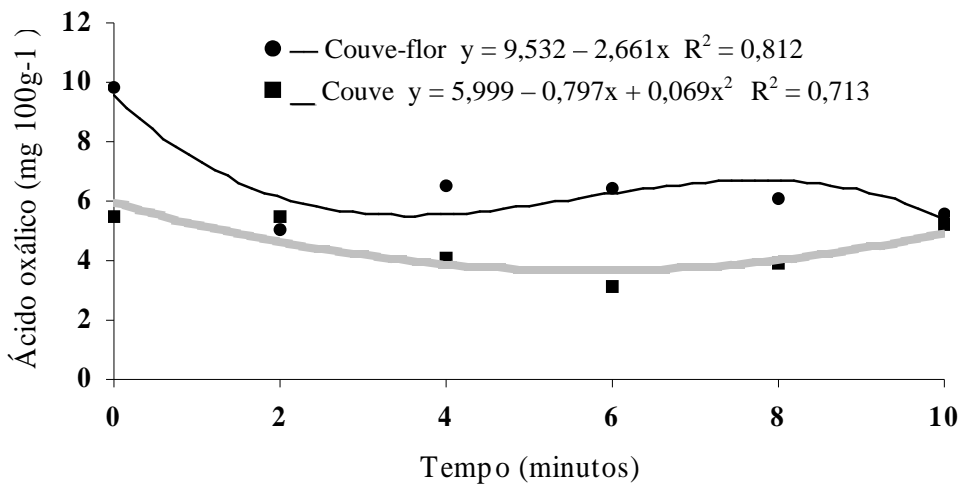

FIGURA 6 - Curvas e equações de regressão representativas dos teores médios de ácido oxálico das espécies couveflor e couve, submetidas a seis tempos de cozimento, expressos em peso fresco.

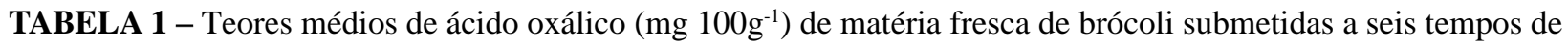
cozimento.

\begin{tabular}{cccccccc}
\hline \multicolumn{7}{c}{ Tempo (minutos) } \\
\hline Médias & 0 & 2 & 4 & 6 & 8 & 10 \\
\hline
\end{tabular}

TABEAL 2 - Resumo das análises de variância de polifenóis, nitrato e ácido oxálico, das espécies de brócoli, couve-flor e couve, submetidas a seis tempos de cozimento (peso fresco).

\begin{tabular}{lcccc}
\hline & & \multicolumn{3}{c}{ Quadrados Médios } \\
\cline { 3 - 5 } Causas da variação & GL & Polifenóis & Nitrato & Ácido oxálico \\
\hline Espécies & 2 & $19062,6623^{* *}$ & $1222,3958^{* *}$ & $26,0365^{* *}$ \\
Tempo & 5 & $39815,1390^{* *}$ & $1545,3868^{* *}$ & $8,5815^{* *}$ \\
Espécies x Tempo & 10 & $3157,7073^{* *}$ & $94,7347^{* *}$ & $4,9004^{* *}$ \\
Resíduo & 36 & 335,7441 & 20,114 & 1,7068 \\
\hline C.V $(\%)$ & & 11,553 & 16,467 & 21,982 \\
\hline
\end{tabular}

** Teste $\mathrm{F}$ significativo a $1 \%$ de probabilidade.

TABELA 3 - Resumo das análises de variância de polifenóis, nitrato e ácido oxálico, das espécies de brócoli, couve-flor e couve, submetidas a seis tempos de cozimento (matéria seca).

\begin{tabular}{lcccc}
\hline & & \multicolumn{3}{c}{ Quadrados Médios } \\
\cline { 3 - 5 } Causas da variação & GL & Polifenóis & Nitrato & Ácido oxálico \\
\hline Espécies & 2 & $2950440,2070^{* *}$ & $97818,4292^{* *}$ & $2267,7247^{* * *}$ \\
Tempo & 5 & $189619,8871^{* *}$ & $57053,2276^{* *}$ & $53,0799^{\text {N.S }}$ \\
Espécies x Tempo & 10 & $52613,4947^{* *}$ & $3835,8843^{*}$ & $228,7345^{\text {N.S }}$ \\
Resíduo & 36 & 8458,6032 & 1608,4588 & 137,2479 \\
\hline C.V $(\%)$ & & 6,511 & 18,393 & 23,702 \\
\hline
\end{tabular}

N.S/*/** Teste F não-significativo, significativo a 5\% e 1\% de probabilidade, respectivamente. 


\section{CONCLUSÕES}

Das substâncias analisadas, apenas os polifenóis apresentaram teores acima daqueles considerados ideais para o consumo, principalmente nas folhas secas de couve e brócoli. $\mathrm{O}$ ácido oxálico não mostrou ser um fator preocupante, sendo que, os teores presentes não são suficientes para influenciar a disponibilidade do cálcio no organismo.

Todas as espécies apresentaram redução nos teores de fatores antinutricionais com o aumento do tempo de cozimento, procedimento recomendado para a redução ou eliminação dessas substâncias nas folhas das brássicas avaliadas. No entanto, os polifenóis ainda se mostraram elevados mesmo após a aplicação dos tratamentos, sugerindo que o tempo máximo de fervura aplicado não foi suficiente para reduzi-los a teores aceitáveis ao consumo humano. Enfim, para utilização dessas hortaliças em peso seco, recomenda-se o cozimento prévio para diminuição dos teores de substâncias antinutricionais, principalmente polifenóis.

No geral, as folhas de couve-comum apresentaram teores médios dos fatores antinutricionais e comportamento durante a aplicação dos tratamentos semelhantes aos observados nas outras espécies. Os resultados evidenciaram a semelhança das folhas de couve tradicionalmente consumidas, com as folhas geralmente desprezadas durante o preparo dos alimentos. Assim, considerando-se os aspectos antinutricionais das folhas de brássicas estudadas, o descarte das folhas de brócoli e couve-flor não é justificado, podendo essas serem consumidas na dieta habitual.

\section{AGRADECIMENTOS}

Ao CNPq pela concessão da bolsa de mestrado. Às professoras Vânia Déa de Carvalho e Celeste Maria Patto de Abreu pela oportunidade de trabalho e ensinamentos.

\section{REFERÊNCIAS BIBLIOGRÁFICAS}

AMBROSONE, C. B.; MCCANN, S. E.; FREUDENHEIM, J. L.; MARSHALL, J. R.; ZHANG, Y.; SHIELDS, P. G. Breast cancer risk in premenopausal women is inversely associated with consumption of broccoli, a source of isothiocyanates, but is not modified by GST genotype. Journal of Nutrition, Philadelphia, v. 134, p. 1134-1138, 2004.
ASSOCIATION OF OFFICIAL ANALYTICAL CHEMISTS. Official methods of analysis. 15. ed. Washington, 1990. v. 2.

BLOCK, G. Vitamin C and cancer prevention: the epidemiologic evidence. American Journal of Clinical Nutrition, New York, v. 53, p. 270-282, 1991.

CATALDO, D. A.; HAROON, M.; SCHRADER, L. E.; YOUNGS, V. L. Rapid calorimetric determination of nitrate in plant tissue by nitration of salicytic acid. Soil Plant Analysis, Athens, v. 6, n. 1, p. 71-80, 1975.

CHUNG, K. T.; WONG, T. Y.; WEI, C. I.; HUANG, Y. W.; LIN, Y. Tannins and human health: a review. Critical Reviews in Food Nutrition, Amherst, v. 38, n. 6, p. 421-464, 1998.

ESPÍNDOLA, F. S. Fracionamento dos vegetais verdes e obtenção de concentrados protéicos de folhas (CPF) para suplementação de alimentos e ração animal, com aproveitamento dos subprodutos. 1987. 130 f. Monografia (Especialização) Universidade Federal de Uberlândia, Uberlândia, 1987.

FRANCO, G. Tabela de composição química dos alimentos. 7. ed. Rio de Janeiro: Atheneu, 1986. 145 p.

GEHM, B. D.; McANDREWS, J. M.; CHIEN, P. Y.; JAMESON, J. L. Resveratrol, a polyphenolic compound found in grapes and wine, is na agonist for the estrogen receptor.Proceedings of the National Academy of Sciences, Washington, v. 94, n. 25, p. 14138-14143, Dec. 1997.

GRIFFITHS, D. W.; BIRCH, A. N. E.; HILLMAN, J. R. Antinutritional compounds in the Brassicaceae: analysis, biosynthesis, chemistry and dietary effects. Journal of Horticultural Science and Biotechnology, Invergowrie, v. 73, n. 1, p. 1-18, 1998.

GUADAGNIN, S. G. Avaliação do teor de nitrato em hortaliças folhosas produzidas por diferentes sistemas de cultivo. 2004. 78 f. Dissertação (Mestrado em Ciências de Alimentos) - Universidade Estadual de Campinas, Campinas, 2004.

GUZMÁN-MALDONADO, S. H.; ACOSTA-GALLEGOS, J.; PAREDES-LÓPEZ, O. Protein and mineral content of a novel collection of wild and weed common bean (Phaseolus vulgaris L.). Journal of the Science of Food and Agriculture, London, v. 80, n. 13, p. 1874-1881, Oct. 2000.

Ciênc. agrotec., Lavras, v. 30, n. 2, p. 294-301, mar./abr., 2006 
HASLAN, E. Chemistry of vegetable tannic. New York: Academic, 1966. 179 p.

HOSENEY, R. C.; VARRIANO-MARSTON, E.; DENDY, D. A. V. Sorghum and millets. Advances in Cereal Science and Tecnology, Saint Paul, v. 4, p. 71-144, Sept./Oct. 1981.

JANG, M.; CAI, L.; UDEANI, G. O.; SLOWING, K. V.; THOMAS, C. F.; BEECHER, C. W.; FON, H. H.; FARNSWORTH, N. R.; KINGHORN, A. R.; MEHTA, R. G.; MOON, R. C.; PEZZUTO, J. M. Cancer chemopreventive activity of resveratrol, a natural product derived from grapes. Science, London, v. 275, n. 5297, p. 218-220, Jan. 1997.

KRAUSE, M. V.; MAHAN, L. K. Alimentos, nutrição e dietoterapia. Tradução de A. R. Almeida et al. São Paulo: Roca, 1991. 981 p. Título original: Food, nutrition and diet therapy.

LELIS, C. C. R.; GONÇALVES, A. de C. Teores de taninos da casca da madeira de cinco leguminosas arbóreas. Floresta e Ambiente, [S.1.], v. 8, n. 1, p. 167-173, jan./dez. 2001.

LIENER, I. E. Implications of antinutritional components in soybean foods. Critical Reviews in Food Science and Nutrition, Cleveland, v. 34, n. 1, p. 31-67, 1994.

LINDSAY, R. C. Aditivos alimentares. In: FENNEMA, O. R. Química de los alimentos. 2. ed. Zaragoza: Acribia, 1993. cap. 10, p. 709-773.

MASSEY, L. K.; ROMAN-SMITH, H.; SUTTON, R. A. L. Effect of dietary oxalate and calcium on urinary oxalate and risk of formation of calcium oxalate kidney stones. Journal of the American Dietetic Association, [S.1.], v. 93, n. 8, p. 901-906, 1993.

MANDEL, N. Mechanism of stone formation. Seminars in Nephrology, [S.1.], v. 16, p. 354-374, 1996.

MEAH, M. N.; HARRISON, N.; DAVIES, A. Nitrate and nitrite in foods and the diet. Food Additives and Contaminants, [S.1.], v. 11, p. 519-532, 1994.

MINISTRY OFAGRICULTURE, FISHERIES AND FOOD. Nitrate, Nitrite and n-Nitroso: compounds in food. London: H. M. Stationery, 1897.
MOSHA, T. C.; GAGA, H. E.; PACE, R. D. Effect of blanching on the content of antinutritional factors in selected vegetsbles. Plant Foods for Human Nutrition, London, v. 47, p. 361-367, Oct. 1995.

PEREIRA, G. I. S.; PEREIRA, R. G. F. A.; BARCELOS, M. F. P.; MORAIS, A. R. Avaliação química da folha de cenoura visando ao seu aproveitamento na alimentação humana. Ciência e Agrotecnologia, Lavras, v. 27, n. 4, p. 852-857, jul./ago. 2003.

PINTO, N. A. V. D.; CARVALHO, V. D.; CORRÊA, A. D.; RIOS, A. O. Avaliação de fatores antinutricionais das folhas da taioba (Xanthosoma sagittifolium SCHOOT). Ciência e Agrotecnologia, Lavras, v. 25, n. 3, p. 601-604, maio/jun. 2001.

REINOLD, R. M. Produtos utilizados para melhorar a estabilidade físico-química da cerveja. Engarrafador Moderno, [S.1.], n. 52, p. 56-58, jul./ago. 1997.

REYES-MORENO, C.; PAREDES-LÓPEZ, O. Hard-to-cook phenomenon in common beans: a review. Critical Reviews in Food Science and Nutrition, Cleveland, v. 33, n. 3, p. 227-286, 1993.

SANTOS, M. A. T. Caracterização química das folhas de brócoli e couve-flor (Brassica oleracea L.) para utilização na alimentação humana. 2000. 96 p. Dissertação (Mestrado em Ciência dos Alimentos) - Universidade Federal de Lavras, Lavras, 2000.

SWAIN, T.; HILLIS, W. G. The phenolic constituents of Prunus domestica: the quantitative analysis of phenolic constituents. Journal of the Science of Food and Agriculture, London, v. 10, p. 63-68, Jan. 1959.

WALKER, R. Naturally accuring nitrate/nitrite in foods. Journal of the Science of Food and Agriculture, London, v. 26, n. 11, p. 1735-1742, Nov. 1975.

WALKER, R. Nitrates, nitrites and N-nitroso compounds: a review of the occurrence in food and diet and the toxicological implications. Food Additives and Contaminants, [S.1.], v. 7, p. 717-768, 1990.

ZONTA, E. P.; MACHADO, A. A. Manual do SANEST: sistema de análise estatística para microcomputadores. Pelotas: UFPl, 1991. 120 p. 